\title{
Metronidazole resistance of Trichomonas vaginalis as a cause of treatment failure in trichomoniasis
}

\section{A case report}

\author{
JAROSLAV KULDA, MILENA VOJTĚCHOVSKÁ, JAN TACHEZY, PAVOL \\ DEMEŚ, AND EVA KUNZOVÁ \\ From the Department of Parasitology, Charles University, Prague; and the Laboratory of Clinical \\ Parasitology, University Hospital 1, Prague, Czechoslovakia
}

SUMMARY Six isolates of a strain (MRP-MT) of Trichomonas vaginalis obtained from a woman before and after unsuccessful treatment with metronidazole had an appreciably lower susceptibility to metronidazole both in vitro in the aerobic tube assay and in vivo in the mouse assay than did control strains from patients cured with standard doses of the drug.

Our results support recent evidence that metronidazole-resistant strains of $T$ vaginalis do cause treatment failure. Resistance of these strains could be detected in vitro under only aerobic but not anaerobic conditions. The prevalence of metronidazole-resistant strains of $T$ vaginalis should be kept under surveillance in order to estimate their clinical importance.

The patient harbouring the resistant strain MRP-MT was finally cured with increased doses of ornidazole.

\section{Introduction}

Resistance of Trichomonas vaginalis to 5-nitroimidazole drugs has been a matter of controversy. ${ }^{1}$ Although drug resistance of trichomonads has not been shown convincingly in vitro there have been clinical reports of treatment failures. The possibility of the existence of metronidazole-resistant strains of $T$ vaginalis has been met with considerable scepticism..$^{2-4}$ Persistent trichomonal infections which could not be ascribed to reinfection were attributed to altered pharmacokinetics in patients ${ }^{5}$ or to a lowering of the drug concentration in the vagina by concomitant bacteria. ${ }^{4} 67$ Recently, however, a decreased susceptibility to metronidazole has been proved unequivocally in several strains of $T$ vaginalis isolated from patients who were refractory to treatment. $^{8-10}$

Meingassner et $a l^{11}$ showed the importance of assay conditions in the in-vitro detection of resistance of trichomonads to 5-nitroimidazoles. Using a laboratory-developed drug-resistant strain of the

Address for reprints: Dr J Kulda, Department of Parasitology, Charles University, 12844 Prague 2, Viniěná 7, Czechoslovakia

Accepted for publication 17 July 1982 cattle parasite Tritrichomonas foetus ${ }^{12}$ these workers found that the resistance of this strain could be ascertained in vitro only under aerobic conditions. Aerobic assay systems have been developed to allow reliable determinations of trichomonad susceptibility to 5-nitroimidazoles in vitro. 810

We report metronidazole resistance in a strain of $T$ vaginalis isolated from a female patient who did not respond to several courses of treatment with 5-nitroimidazoles. ${ }^{13}$

\section{Patient and methods}

CASE REPORT

The patient was a 41-year-old woman who gave a four-year history of recurrent vulvo-vaginitis caused by $T$ vaginalis. During this period she had been treated unsuccessfully seven times with metronidazole (Entizole, Polfa) and once with tinidazole (Fasigyn, Pfizer). In five of the treatment courses metronidazole $(250 \mathrm{mg})$ was taken orally twice daily supplemented with $500 \mathrm{mg}$ inserted vaginally once daily for 10 days. In one course the daily dose of metronidazole was increased to $1 \mathrm{~g}$, and in another five $250-\mathrm{mg}$ oral tablets (a total of $1250 \mathrm{mg}$ metronidazole) were taken daily for three days. 
Tinidazole was given orally in $150 \mathrm{mg}$ tablets twice daily for seven days.

When she was examined in our department the patient had an acute vulvo-vaginitis with an inflammatory discharge containing many trichomonads (isolate MRP-MT-1). She was given two successive courses of treatment with oral metronidazole (Flagyl, Specia) in a dosage of $500 \mathrm{mg}$ twice daily for five days. Similar treatment was given to her husband. After completion of the treatment the symptoms disappeared and no trichomonads were found in a wet mount preparation. $T$ vaginalis was cultured), however, from vaginal material (isolate MRP-MT-3). Within a month the symptoms had returned and numerous trichomonads were detected in the vaginal exudate.

To determine whether the treatment failure was due to poor absorption of metronidazole the patient was admitted to hospital and given metronidazole in a single oral dose of $2 \mathrm{~g}$. The serum concentrations of the drug were determined two, four, and 24 hours after treatment. Satisfactory concentrations of metronidazole were present in the serum (table I). The treatment was completed by giving the patient metronidazole in a dosage of $1 \mathrm{~g}$ twice daily for seven days. Despite symptomatic relief and the reappearance in the vagina of Lactobacillus vaginalis trichomonads were cultured from vaginal material (MRP-MT-8). The patient was eventually cured with ornidazole (Tiberal, Roche) $1 \mathrm{~g}$ orally twice daily supplemented with $500 \mathrm{mg}$ inserted vaginally once daily for six days. The symptoms disappeared completely and $T$ vaginalis could not be cultured from vaginal material.

TABLE I Serum concentrations of metronidazole after administration of a single oral dose of $2 \mathrm{~g}$ (polarographic determinations at $-0.7 \mathrm{~V}$ )

\begin{tabular}{ll}
\hline $\begin{array}{l}\text { Hours after } \\
\text { administration of drug }\end{array}$ & $\begin{array}{l}\text { Serum metronidazole concentration } \\
(\mu \mathrm{g} / \mathrm{ml})\end{array}$ \\
\hline 4 & 33 \\
8 & 25 \\
24 & 12 \\
\hline
\end{tabular}

ISOLATION AND CULTIVATION OF T VAGINALIS The metronidazole-resistant strain under study, $T$ vaginalis MRP-MT, was isolated from the vagina of the patient on several occasions before and after unsuccessful treatment. A total of eight isolates were obtained during the two-year study of the patient. Six of these isolates were assayed for susceptibility to metronidazole in vitro.

Eight strains of $T$ vaginalis which were susceptible to metronidazole (TV5-27, TV7-37, TV10-02, TV14-85, TV17-48, TV67-77, TV87-64, and
TV99-51) were isolated from patients who had attended our clinic. All patients had been successfully treated with a single course of oral metronidazole.

Trichomonads were isolated from vaginal secretions collected with a cotton swab from the posterior fornix of the vagina. Cultures were established and maintained in Diamond's (trypticase, yeast extract, maltose) medium (TYM), ${ }^{14} \mathrm{pH} \mathrm{6.0}$ with trypticase (BBL) replaced by tryptone (Oxoid, L-42). The medium was supplemented with $10 \%$ heat-inactivated horse serum. Concomitant microorganisms were eliminated by migration in the DeCarneri tube ${ }^{15}$ and with the aid of antibiotics. All isolates were treated three times with kanamycin sulphate $(2500 \mu \mathrm{g} / \mathrm{ml})$, three times with penicillin $\mathrm{G}$ $(5000,2000$ and $1000 \mathrm{IU} / \mathrm{ml})$ and once with streptomycin sulphate $(1000 \mu \mathrm{g} / \mathrm{ml})$. The absence of contaminating micro-organisms was confirmed by standard sterility tests including assays for Mycoplasma spp. Axenised cultures with the addition of $5 \%$ dimethylsulphoxide were stored in liquid nitrogen.

The two reference metronidazole-resistant strains, obtained by courtesy of Dr J G Meingassner, Sandoz Forschungsinstitut, Vienna, were $T$ vaginalis IR-78 from Vienna, Austria, ${ }^{8}$ and $T$ vaginalis "Fall River" from the USA. ${ }^{10}$ The former was a fresh subculture of the original stabilate, ${ }^{8}$ and the latter had been maintained for several months by serial transfers. Both strains had been grown axenically. After arrival at our laboratory the strains were transferred to TYM medium and cryopreserved.

Cultures used in the experiments were derived from frozen stabilates and grown in TYM medium without antibiotics. Except for the "Fall River" strain, none of the strains was maintained in active culture at $37^{\circ} \mathrm{C}$ for longer than three weeks.

\section{SUSCEPTIBILITY ASSAYS}

Susceptibility of trichomonads to metronidazole in vitro was estimated as a minimal lethal concentration (MLC) of the drug using an aerobic tube assay. Suspensions of trichomonads $\left(1 \times 10^{5}\right.$ cells $\left./ \mathrm{ml}\right)$ in 1 $\mathrm{ml}$ of the aerobic medium (TYM without cysteine and ascorbic acid) were exposed for 48 hours to twofold serial dilutions of metronidazole, and the viability of the parasites was assayed by subsequent cultivation in a drug-free medium. The assay was performed in $100 \times 15 \mathrm{~mm}$ centrifuge tubes, each containing $0.9 \mathrm{ml}$ of a suspension of parasites in the aerobic TYM and $0.1 \mathrm{ml}$ of the metronidazole solution. The tubes were closed with metal caps allowing equilibration with air. After incubation at $37^{\circ} \mathrm{C}$ for 48 hours the cells were centrifuged $(1600 \times g)$, washed in saline, and resuspended in $5 \mathrm{ml}$ of standard TYM. The metal caps were replaced by 
non-toxic rubber stoppers and the tubes incubated at $37^{\circ} \mathrm{C}$ for seven days. The MLC at 48 hours $\left(\mathrm{MLC}_{48 \mathrm{~h}}\right)$ was defined as the lowest concentration of metronidazole at which no viable trichomonads could be detected by cultivation. The assays were run in duplicate and repeated at least twice; additional dilutions were included to refine endpoints.

The in-vitro susceptibility to metronidazole was assayed also under anaerobic conditions in $13 \times 100$ $\mathrm{mm}$ screw-cap tubes (Bellco). Each tube contained $4.4 \mathrm{ml}$ of standard TYM (with reducing compounds included), $0.1 \mathrm{ml}$ of metronidazole solution, and 0.5 $\mathrm{ml}$ of trichomonad suspension (to make a final concentration of $1 \times 10^{5}$ cells $\left./ \mathrm{ml}\right)$. After 48 hours exposure to metronidazole the cells were washed with saline and resuspended in a drug-free medium.

The in-vivo susceptibility to metronidazole was assayed by estimating the $\mathrm{DC}_{50}$ (dose needed to cure $50 \%$ of infections) using the subcutaneous mouse assay described by Meingassner and Thurner. ${ }^{8}$ Mice were inoculated subcutaneously in each flank with trichomonads which were in the logarithmic phase of growth. Metronidazole was given orally at two, 18, and 24 hours after inoculation. The therapeutic effect was evaluated on day 6 by determining whether viable parasites were present or absent at the site of inoculation (by microscopy and culture). Male albino SPF mice (18-20 g) supplied by Velaz (Prague, Czechoslovakia) were ușed in preliminary experiments performed in Prague. Thirty mice were inoculated with $T$ vaginalis isolate MRP-MT-3 and 30 received the susceptible control strain TV17-48. The inocula contained $1 \times 10^{6}$ cells in $0.5 \mathrm{ml}$ of TYM medium. Groups of six mice were given the same dose of metronidazole. Further experiments on the metronidazole-resistant isolate MRP-MT-3 were performed by $J$ G Meingassner in Vienna. Female NMRI mice (weight 10-12 g), supplied by Gassner (Salzberg, FRG) were inoculated subcutaneously and intraperitoneally. A total of 55 mice (two experiments) were inoculated subcutaneously (inocula $4 \times 10^{5}$ cells) and 118 mice (three experiments) intraperitoneally $\left(1.2 \times 10^{6}\right.$ cells $)$. The same dose of the drug was given to groups of seven or eight mice. Untreated controls were included in the experiments. Curative doses were determined by means of a probit analysis.

\section{METRONIDAZOLE}

Pure metronidazole produced by Specia or Bayer was used throughout the experiments. For in-vitro assays stock solutions were prepared in glass-distilled water $(50 \mathrm{mg} / 10 \mathrm{ml})$, and the substance was dissolved by autoclaving. Serial dilutions were made in aerobic TYM. For mouse assays the drug was dissolved and administered in a $10 \%$ aqueous solution of dimethylsulphoxide and $0 \cdot 2 \%$ Tween $80(\mathrm{v} / \mathrm{v})$.

SERUM CONCENTRATIONS OF METRONIDAZOLE Serum concentrations of metronidazole were determined polargraphically by the method of Kane ${ }^{16}$ using an LP-60 polarograph (Laboratory Supplies, Prague) at $-0.7 \mathrm{~V}$. Before the measurement the sera were diluted $1 / 10$ with potassium chloride (final $\mathrm{KCl}$ concentration $0 \cdot 001 \mathrm{~mol} / \mathrm{l}$ ).

\section{Results}

The data summarised in table II showed notable differences between the in-vitro susceptibility to metronidazole of MRP-MT isolates and that of control $T$ vaginalis strains from patients responding favourably to a standard treatment. In an aerobic tube assay the mean $\mathrm{MLC}_{48 \mathrm{~h}}(81 \mu \mathrm{g} / \mathrm{ml})$ for the MRP-MT isolates was about 29 times higher than that for the control strains (TV) $(2 \cdot 8 \mu \mathrm{g} / \mathrm{ml})$. The MLCs for the MRP-MT isolates were within the range of those for the reference metronidazoleresistant strains from Austria (IR-78) and the USA ("Fall River"). The resistance in vitro was detectable only in the aerobic assay. Under anaerobic conditions all assayed strains were susceptible to metronidazole with a mean $\mathrm{MLC}_{48 \mathrm{~h}}$ of $2 \cdot 15 \mu \mathrm{g} / \mathrm{ml}$.

When the efficacy of metronidazole against infection with the isolate MRP-MT-3 was further assayed in vivo in subcutaneously and intraperitoneally infected mice the susceptibility of this isolate to metronidazole was low (table III). Its relative drug resistance was more pronounced in mice which had been inoculated subcutaneously. The DC $_{50}$ value of the MRP-MT-3 isolate, calculated from the subcutaneous assays performed in Prague, was about 20 times higher than that of the drugsusceptible control TV 14-85. The highest dose given $(3 \times 800 \mathrm{mg} / \mathrm{kg})$ was insufficient to obtain a $100 \%$ cure. In Meingassner's experiments none of the mice infected subcutaneously was cured with the highest dose assayed $(3 \times 400 \mathrm{mg} / \mathrm{kg})$. Intraperitoneal infections with the MRP-MT-3 isolate were successfully cured with metronidazole. The doses necessary for eliminating the infection, however, were relatively high $(3 \times 400 \mathrm{mg} / \mathrm{kg})$ and the $\mathrm{DC}_{50}$ values about eight times higher than that for the Viennese control strain E (table III).

The MLC values for six isolates of the MRP-MT strain (table II) showed that throughout the two years of study the protozoon did not respond to repeated treatment by an increase in resistance. 
TABLE II In-vitro susceptibility to metronidazole of $T$ vaginalis MRP-MT isolates compared with reference metronidazoleresistant strains (IR-78 and Fall River) and eight drug-susceptible strains

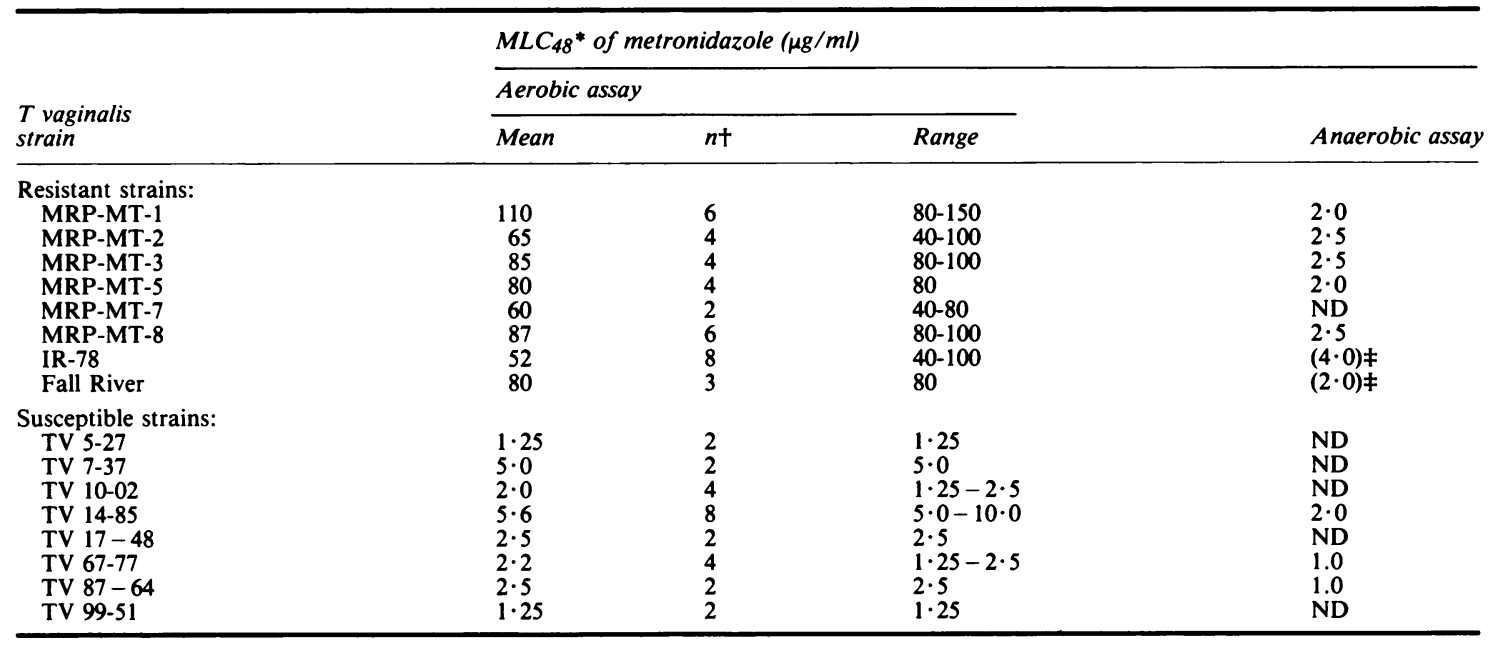

* Minimal lethal concentration of metronidazole after $48 \mathrm{~h}$ exposure of parasites to the drug

tNumber of determinations

¥Data from reference 10 obtained by anaerobic tray test

$\mathrm{ND}=$ not determined

TABLE III In-vivo susceptibility to metronidazole of the T vaginalis isolate MRP-MT-3 compared with the drug-susceptible strains $T V 14-85$ and $E$

\begin{tabular}{|c|c|c|c|c|c|}
\hline \multirow[b]{2}{*}{ Strain } & \multirow[b]{2}{*}{ Assayed by } & \multicolumn{2}{|c|}{ Subcutaneous assay } & \multicolumn{2}{|c|}{ Intraperitoneal assay } \\
\hline & & $\begin{array}{l}\text { No of } \\
\text { mice }\end{array}$ & $\begin{array}{l}D C_{50} \\
(\mathrm{mg} / \mathrm{kg})(\times 3)^{*}\end{array}$ & $\begin{array}{l}\text { No of } \\
\text { mice }\end{array}$ & $\begin{array}{l}D C_{50} \\
(\mathrm{mg} / \mathrm{kg})(\times 3)\end{array}$ \\
\hline MRP-MT-3 & $\begin{array}{l}\text { Kulda et al } \\
\text { Meingassner }\end{array}$ & $\begin{array}{l}30 \\
55\end{array}$ & $\begin{array}{r}300 \\
>400\end{array}$ & 94 & 115.9 \\
\hline $\begin{array}{l}\text { TV 14-85 } \\
\text { Et }\end{array}$ & $\begin{array}{l}\text { Kulda et al } \\
\text { Meingassner }\end{array}$ & 30 & $\begin{array}{l}15 \\
11 \cdot 2\end{array}$ & & $14 \cdot 7$ \\
\hline
\end{tabular}

*Dosage of metronidazole given orally at two, 18 , and $24 \mathrm{~h}$

tData on this strain is given in reference ${ }^{8}$

\section{Discussion}

Our results showed a relative resistance to metronidazole of the $T$ vaginalis strain MRP-MT isolated in Prague from a patient with a resistant vulvo-vaginitis. Neither reinfection nor failure to take the prescribed doses of the drug could be regarded as being responsible for the persistent infection, because one of the unsuccessful courses of treatment was given while she was in hospital. Serum concentrations of metronidazole after oral administration indicated satisfactory absorption of the drug from the gut. The resistance of the trichomonads isolated from the patient was shown in laboratory assays under bacteria-free conditions, thereby excluding any interference by bacteria in the trichomonocidal ability of the drug. The low susceptibility of the MRP-MT strain to metronidazole was detected in vitro by an aerobic tube assay as well as in vivo by determining the $C_{50}$ in mice infected subcutaneously and intraperitoneally. The reliability of the laboratory tests was controlled by assaying in parallel the MRPMT isolates, the reference metronidazole-resistant strains, and drug-susceptible strains isolated from patients cured successfully with standard doses of metronidazole. These data indicated that infection with a metronidazole-resistant strain was the primary cause of the treatment failure in our patient.

The properties of the MRP-MT strain were similar to those described recently by other workers. ${ }^{81017}$ All these strains caused treatment-resistant diseases in man; their resistance was detected in vivo in subcutaneously infected mice and also in vitro if assay conditions were aerobic. The importance of using an aerobic system for the in-vitro demon- 
stration of resistance was confirmed by others. ${ }^{18}$ Forsgren and Forssman ${ }^{9}$ identified their metronidazole-resistant strain using a tube assay which appeared to be essentially aerobic. On the other hand, the relatively low minimum inhibitory concentrations (MICs) reported for strains of $T$ vaginalis from treatment failures in Britain (MIC 20-25 $\mu \mathrm{g} / \mathrm{ml}$ ) might have been accounted for by the use of an assay system in which there is a lower availability of oxygen. ${ }^{19} 20$

The need for aerobic conditions to show resistance in an anaerobic organism seems to be an unusual phenomenon. Persisting doubts on the real existence of metronidazole-resistant strains of $T$ vaginalis are therefore understandable. Incomplete anaerobiosis was the cause of a false metronidazole "resistance" in anaerobic bacteria. ${ }^{21}$ Even in trichomonads the presence of air suppressed the uptake of metronidazole ${ }^{22}$ and increased MLC values of the drug. ${ }^{11}$ Recently published comparative data ${ }^{8-10}$ have shown differences in aerobic MLC values between $T$ vaginalis strains isolated from readily curable trichomoniasis and from a treatment-resistant infection. This evidence is supported by the results of our study.

Laboratory experiments indicated that the resistance of $T$ vaginalis to metronidazole involves an aerobic tolerance to the drug. Implications of this phenomenon for the drug-parasite interaction in situ need to be clarified. The number of resistant trichomonads in the vagina is appreciably reduced after treatment with metronidazole. Probably very few potentially resistant trichomonads meet with conditions in the human vagina which favour their aerobic drug-tolerance. Data on oxygen tension and redox potential in different parts of the infected vagina would clarify the physiological background of infections with metronidazole-resistant trichomonads. Biochemical mechanisms of $T$ vaginalis resistance to metronidazole are not yet known. ${ }^{23}{ }^{24}$ There is some evidence, however, that this aerobic type of resistance is not connected with enzyme deficiences eliminating the pathway of anaerobic pyruvate metabolism essential for activation of 5-nitroimidazoles. Such enzyme lesions have been observed in metronidazole-resistant mutants of Tritrichomonas foetus 2526 and Bacteroides fragilis ${ }^{27}$ but not in the drug-tolerant $T$ vaginalis. 242829

Metronidazole resistance of the strain of $T$ vaginalis MRP-MT which was reisolated repeatedly from the vagina of our patient did not increase as a result of three unsuccessful courses of treatment; each of the courses apparently exerted considerable selection pressure on the trichomonads. Similarly, increase in resistance was not observed in a strain of
$T$ vaginalis isolated in Sweden after treatment with tinidazole. ${ }^{9}$ In both cases, however, the patients had been treated with nitroimidazoles before initial isolation of the parasite. It is uncertain whether the resistance was induced by inadequate treatment or was intrinsic to the infecting organism.

Recent evidence indicates that metronidazoleresistant strains of $T$ vaginalis cannot be regarded as unique in their incidence. Isolation of resistant strains from patients have been reported in Austria, ${ }^{8}$ Sweden, ${ }^{9}$ Britain, ${ }^{1920}$ and the USA. ${ }^{1017} 18$ This calls for a systematic follow-up of treatment failures and extensive surveys of a random population to establish the prevalence of resistant strains. Until then it would be premature to draw conclusions on the clinical importance of metronidazole resistance in strains of $T$ vaginalis. In view of the absence of clinically available drugs which could replace 5-nitroimidazoles, however, the resistance of $T$ vaginalis to metronidazole should be followed with concern.

We wish to thank Dr J G Meingassner (Sandoz Forschungsinstitut, Vienna, Austria) for assaying the in-vivo efficacy of metronidazole against our $T$ vaginalis isolate and for his generous permission to publish his data in this paper. We also appreciate $\mathrm{Dr}$ Meingassner's help in providing the reference metronidazole-resistant strains of $T$ vaginalis. Our sincere thanks are due to Dr M Müller (Rockefeller University, New York, USA) for his kind permission to use his metronidazole-resistant strain and for sending us reprints of his papers, to Dr J Čerkasov (Charles University, Prague, Czechoslovakia) for his valuable advice on a polarographic determination of metronidazole, and to our patient for her patience and co-operation.

\section{References}

1. Honigberg BM. Trichomonads of importance in human medicine. In: Kreier JP, ed. Parasitic Protozoa, vol II. New York: Academic Press, 1978:275-454.

2. Korner B, Jensen HK. Sensitivity of Trichomonas vaginalis to metronidazole, tinidazole, and nifuratel in vitro. $\mathrm{Br} J$ Vener Dis 1976;52:404-8.

3. Roe FJC. Metronidazole: review of its uses and toxicity. $J$ Antimicrob Chemother 1977;3:205-12

4. Edwards DI. Mechanisms of selective toxicity of metronidazole and other nitroimidazole drugs. Br J Vener Dis 1980;56:285-90.

5. Kane PO, McFadzean JA, Squires S. Absorption and excretion of metronidazole. II Studies on primary failures. $\mathrm{Br} J$ Vener Dis 1961;37:276-7.

6. Ralph ED, Clarke DA. Inactivation of metronidazole by anaerobic and aerobic bacteria. Antimicrob Agents Chemother 1978;14:377-83.

7. Edwards DI, Thompson EJ, Tomusange J, Shanson D. Inactivation of metronidazole by aerobic organisms. $J$ Antimicrob Chemother 1979;5:315-6.

8. Meingassner JG, Thurner J. Strain of Trichomonas vaginalis resistant to metronidazole and other 5-nitroimidazoles. Antimicrob Agents Chemother 1979;15:254-7.

9. Forsgren A, Forssman L. Metronidazole-resistant Trichomonas vaginalis. Br J Vener Dis 1979;55:351-3. 
10. Müller M, Meingassner J, Miller WA, Ledger WJ. Three metronidazole-resistant strains of Trichomonas vaginalis from the United States. Am J Obstet Gynecol 1980;138:808-12.

11. Meingassner JG, Mieth H, Czok R, Lindmark DG, Müller M. Assay conditions and the demonstration of nitroimidazole resistance in Trichomonas foetus. Antimicrob Agents Chemother 1978;13:1-3.

12. Meingassner JG, Mieth $\mathbf{H}$. Cross-resistance of trichomonads to 5-nitroimidazole-derivatives. Experientia 1976;32:183-4.

13. Kulda J, Demeš $P$, Vojtěchovská $M$, Kunzová E. Metronidazole resistant strain of Trichomonas vaginalis from a patient refractory to treatment. J Protozool 1980;27:70A

14. Diamond LS. The establishment of various trichomonads of animals and man in axenic cultures. $J$ Parasitol 1957;43:488-90.

15. DeCarneri I. Isolation of Trichomonas vaginalis from fungi and bacteria. Am J Trop Med 1956;5:210-2.

16. Kane PO. Polarographic methods for the determination of two anti-protozoal nitroimidazole derivatives in materials of biological and non-biological origin. $J$ Polarograf Soc 1961;8:58-62.

17. Lossick JG. Metronidazole. N Engl J Med 1981;304:735.

18. Smith RF, DiDomenico A. Measuring the in-vitro susceptibility of Trichomonas vaginalis to metronidazole. Sex Transm Dis 1980;7:120-4.

19. Heyworth R, Simpson D, McNeillage GJC, Robertson DHH, Young $\mathrm{H}$. Isolation of Trichomonas vaginalis resistant to metronidazole. Lancet 1980;ii:476-8.

20. Waitkins S, Thomas DJ. Isolation of Trichomonas vaginalis resistant to metronidazole. Lancet 1981;ii:590.

21. Milne SE, Stokes EJ, Waterworth PM. Incomplete anaerobiosis as a cause of metronidazole "resistance". J Clin Pathol 1978;31:933.
22. Müller M, Lindmark D. Uptake of metronidazole and its effect on viability in trichomonads and Entamoeba invadens under anaerobic and aerobic conditions. Antimicrob Agents Chemother 1976;9:696-700.

23. Müller M. Action of clinically utilized 5-nitroimidazoles on microorganisms. Scand J Infect Dis 1981;suppl 26:31-41.

24. Müller M. Resistance to 5-nitroimidazoles in pathogenic microorganisms. In: Chemistry) Pharmacology and Clinical Application of Nitroimidazoles. Proceedings of the International Conference, Cesenatico, Italy, 27-30 August 1980. Bologna, Italy: Universita Degli Studi di Bologna, in press.

25. Kulda J, Čerkasov J, Čerkasovová A. Tritrichomonas foetus resistant to metronidazole: development of resistance in vitro. In: Progress in Protozoology. Proceedings of the VI International Congress of Protozoology. Abstracts. Warsaw, Poland: 1981:203.

26. Cerkasovová A, Cerkasov J, Kulda J, Demes P. Metronidazole action on Trichomonas foetus: enzyme activities in the strains of a different resistance to the drug. In: Van den Bossche $\mathbf{H}$, ed. Host Invader Interplay. Amsterdam, Netherlands: Elsevier/North-Holland Biomed Press, 1980:669-72.

27. Britz ML, Wilkinson RG. Isolation and properties of metronidazole-resistant mutants of Bacteroides fragilis. Antimicrob Agents Chemother 1979;16:19-27.

28. Müller M. Physiological studies on Trichomonas vaginalis with lowered susceptibility to metronidazole. J Protozool 1980;27:26A-27A.

29. Demes P. Biological properties of metronidazole-resistant trichomonads. Thesis. Prague, Czechoslovakia: Department of Parasitology, Charles University, 1980. 